\title{
ANALISIS SEKTOR BASIS DAN SHIFT-SHARE PEKERJA MENURUT LAPANGAN USAHA PDRB PROPINSI JAWA TIMUR
}

\author{
Lumadya Adi ${ }^{1}$ \\ Jajuk Suprijati2 \\ Rosidah $^{3}$ \\ Vicky Cahya K. ${ }^{4}$ \\ Fakultas Ekonomi dan Bisnis, Universitas Dr. Soetomo, Surabaya 1, 2, 3, 4 \\ Korespondensi Peneliti: Lumadya Adi \\ Email: lumadya.adi@unitomo.ac.id \\ Alamat: Fakultas Ekonomi dan Bisnis, Universitas Dr. Soetomo, Surabaya \\ Jalan Semolowaru 84 Surabaya
}

\begin{abstract}
The province that was the object of the study was East Java with the reason that it had the highest number of agricultural sector workers among the six provinces in Java island in 2011 and 2017. The first objective of this study was to know the base and non-base sectors in the GRDP by Business Field; the second objective is to examine the development of the sector regionally compared to the national and the competitiveness of the sector.

The analytical tools are used: the Location Quotient analysis that is used to analyze the first goal and Shift-share analysis that is used to analyze the second goal.

The results of the analysis are: The results of the LQ analysis for East Java province in 2011 and 2017 have the same base activities namely sector 1. Agriculture, Forestry, Hunting and Fisheries; and sector 2. Mining and quarrying. The results of the Shift Share analysis from 2011 to 2017 for East Java province show National Share all sectors have absorption growth rates regional labor (East Java) is higher than the national level (Java island); in the Industrial Mix column sector 1 is a sector that grows more slowly; in the Competitive Position column 3,5,6,7,8 are sectosr that has low competitiveness.
\end{abstract}

\section{Abstrak}

Propinsi yang menjadi obyek penelitian adalah Jawa Timur dengan alasan memiliki jumlah pekerja sektor pertanian yang paling tinggi diantara enam propinsi di pulau Jawa pada tahun 2011 dan 2017. Tujuan pertama penelitian ini adalah mengetahui sektor basis dan non-basis dalam PDRB Menurut Lapangan Usaha; tujuan kedua adalah menguji perkembangan sektor secara regional bila dibandingkan dengan nasional serta kemampuan daya saing sektor tersebut.

Alat analisis yang dipakai adalah analisis Location Quotient yang dipakai untuk menganalisis tujuan pertama serta analisis Shift-share untuk menganalisis tujuan kedua.

Hasil analisis adalah: Hasil analisis LQ untuk propinsi Jawa Timur pada tahun 2011 dan 2017 memiliki kegiatan basis yang sama yaitu sektor 1. Pertanian,Kehutanan, Perburuan, dan Perikanan; dan sektor 2. Pertambangan dan Penggalian, Hasil analisis Shift Share dari tahun 2011 ke 2017 untuk propinsi Jawa Timur menunjukkan National Share semua sektor memiliki tingkat pertumbuhan penyerapan tenaga kerja regional (Jawa Timur) lebih tinggi bila dibandingkan dengan tingkat nasional (pulau Jawa); pada kolom Industrial Mix sektor 1. Pertanian,Kehutanan, Perburuan, dan Perikanan merupakan sektor yang tumbuh lebih lamban; pada kolom Competitive Position 3,5,6,7,8 merupakan sektor yang memiliki daya saing rendah.

Keyword: location quotient, shift-share, national share, industrial mix, comparative position

\section{PENDAHULUAN}

Propinsi Jawa Timur merupakan salah satu propinsi yang menjadi lumbung pangan nasional. Jawa Timur juga merupakan propinsi yang memberikan lapangan pekerjaan terbanyak kepada para pekerja untuk melakukan aktivitas sehari-hari kepada sektor primer utamanya sektor 1. Pertanian,Kehutanan, Perburuan, dan Perikanan. Data menunjukkan untuk sektor 1 tersebut pada tahun 2011 mampu menyerap 7.520 .067 pekerja, sementara tahun 2017 menyerap 6.713.893 pekerja.

Menurunnya share pekerja pada sektor pertanian dalam Produk Domestik Regional Bruto Propinsi dikawatirkan akibat dari sedikitnya pekerja baru yang masuk ke sektor pertanian dan lebih suka masuk ke sektor industri. Para pemuda enggan untuk bekerja di sektor pertanian dengan pelbagai alasan, dan pergi ke kota 
untuk menjadi pekerja di pabrik-pabrik dan kantor-kantor. Mereka yang memiliki keahlian tertentu akan mendapatkan gaji di atas UMR, dan yang tidak memiliki keahlian dibayar sesuai UMR bahkan banyak pekerja yang mendapatkan upah dibawah UMR. Penurunan share pekerja sektor pertanian terhadap total pekerja dalam PDRB dimungkinkan membawa kerugian pada sektor pertanian berupa kesulitan untuk mendapatkan pekerja sektor pertanian dan naiknya impor produk-produk pertanian.

Badan Pusat Statistik mengelompokkan Pekerja menurut Lapangan Usaha dalam Produk Domestik Regional Bruto Atas Dasar Harga Konstan 2010 ke dalam 9 (sembilan) sektor yaitu: 1. Pertanian,Kehutanan, Perburuan, dan Perikanan; 2. Pertambangan dan Penggalian, 3. Industri Pengolahan, 4. Listrik, Gas, dan Air, 5. Bangunan, 6. Perdagangan Besar, Eceran, Rumah Makan, dan Hotel, 7. Angkutan, Pergudangan, dan Komunikasi, 8. Keuangan, Asuransi, Usaha Persewaan Bangunan, Tanah, dan Jasa Perusahaan, dan 9. Jasa Sosial/perorangan, sementara itu untuk kinerja ekonomi PDRB tersebut terbagi ke dalam 17 sektor ekonomi baik dalam harga berlaku maupun dalam harga konstan 2010.

Dari pekerja sembilan sektor tersebut terbagi ke dalam dua sektor yaitu sektor basis dan sektor nonbasis. Disebut bekerja pada sektor basis (base sector) manakala memiliki nilai LQ $>1$; ataupun disebut bekerja pada sektor non-basis (unbase sector) manakala memiliki nilai LQ $\leq 1$ (Tarigan, 2014: 35). Dalam konteks ekonomi: sektor basis dapat dimaknai sebagai sektor unggulan yang produknya untuk diekspor, sedangkan sektor non-basis sebagai sektor pendukung untuk memenuhi kebutuhan masyarakat wilayah itu sendiri; sedangkan dalam konteks tenaga kerja; sektor i di wilayah kita merupakan sektor basis manakala secara proporsional sektor i tersebut dapat menyediakan lapangan kerja melebihi sektor i secara nasional.

Analisis LQ dilengkapi dengan analisis shift-share (SS). Inti dari analisis SS ini adalah membandingkan laju pertumbuhan pelbagai sektor (industri) di wilayah regional (lebih sempit) dengan wilayah nasional (lebih luas). Jadi analisis SS akan mengurai faktor terjadi pertumbuhan pelbagai sektor di wilayah yang lebih sempit dikaitkan dengan wilayah yang lebih luas. Analisis SS ini juga bisa disebut sebagai industrial mix analysis ((Tarigan, 2014: 85-86).

Beberapa penelitian terkait ketenagakerjaan sektoral dapat dilihat pada paparan berikut:

Nur AR, et al (2015) mengatakan untuk Mojokerto selama tahun penelitian 2009-2013 yang merupakan sektor basis adalah: sektor 1. Pertanian, 2. Pertambangan dan Penggalian, 3. Industri Pengolahan, dan 7. Pengangkutan dan Komunikasi, sedangkan lainnya merupakan sektor bukan basis. Temuan untuk Shift-share adalah: a). Nilai national share semua sektor positif artinya pertumbuhan semua sektor ekonomi Mojokerto memberikan kontribusi positif terhadap penyerapan tenaga kerja di Jawa Timur; b). Nilai Proportional shift yang positif adalah sektor 5). Bangunan dan 6) Perdagangan, Hotel, dan Restoran artinya sektor-sektor tersebut secara nasional tumbuh cepat bila dibandingkan pertumbuhan nasional ; c). Nilai Differential Shift yang positif adalah sub-sektor Jasa Penunjang Angkutan dalam sektor Pengangkutan dan Telekomunikasi maknanya adalah sub sektor itu saja yang memiliki daya saing.

Penelitian ini sangat menarik karena: pertama, propinsi Jawa Timur dikenal sebagai kawasan yang subur untuk sektor pertanian namun sekaligus kawasan yang industrinya dominan di negara kita; kedua, memiliki jumlah pekerja sektor 1. Pertanian dalam PDRB propinsi-propinsi di pulau Jawa merupakan penyumbang terbesar Perbedaan dengan penelitian-penelitian sebelumnya adalah: pertama, kebanyakan penelitian sebelumnya memakai regionalnya adalah kabupaten dan kawasan yang lebih besar adalah propinsi, sedangkan dalam penelitian ini regionalnya adalah propinsi dan kawasan yang lebih besar adalah Nasional (Pulau Jawa); kedua, kebanyakan penelitian sebelumnya memakai regionalnya adalah propinsi dan kawasan yang lebih besar adalah Indonesia, sedangkan dalam penelitian ini regionalnya adalah propinsi dan kawasan yang lebih besar adalah Nasional (Pulau Jawa);

Obyek yang diteliti nantinya adalah data pekerja Menurut Lapangan Usaha dalam Produk Domestik Regional Bruto propinsi Jawa Timur serta data pekerja dalam Produk Domestik Regional Bruto seluruh propinsi di Pulau Jawa. Data pekerja pulau Jawa merupakan penjumlahan data pekerja dalam Produk Domestik Regional Bruto propinsi DKI Jakarta, Banten, Jawa Barat, DI Jogjakarta, Jawa Tengah, dan Jawa Timur.

Dari latar belakang masalah tersebut dapat dirumuskan permasalahan penelitian yaitu:

1). Sektor apakah yang merupakan sektor basis untuk propinsi Jawa Timur tahun 2011 dan 2017 ?

2). Berapakah nilai shift-share pekerja setiap sektor untuk propinsi Jawa Timur dari tahun 2011 ke 2017 ?

Tujuan penelitian adalah: 1). Mengetahui sektor yang menjadi sektor basis untuk propinsi Jawa Timur tahun 2011 dan 2017.; 2). Mengetahui nilai shift-share pekerja setiap sektor untuk propinsi Jawa Timur dari tahun 2011 ke 2017. 
Penelitian ini bermanfaat untuk:

1). Perkembangan ilmu

Penelitian ini dapat dikembangkan lebih lanjut bagi perkembangan ilmu di masa yang akan datang terkait dengan LQ dan SS.

2). Mahasiswa

Pertama, menambah wawasan bagi mahasiswa tentang peranan setiap sektor dan perubahan struktural dalam PDRB propinsi Jawa Timur, kedua, Formula yang ada pada penelitian ini dapat dipakai mahasiswa untuk menyelesaikan tugas mata kuliah terkait dan bisa dipakai untuk menyelesaikan skripsi yang memakai alat analisis LQ dan Shift-share.

3). Pemerintah Daerah

Pertama, mengetahui sektor basis dan non-basis untuk membuat kebijakan lebih lanjut tentang sektor yang perlu dikembangkan lebih lanjut sebagai sektor unggulan ataupun yang tidak perlu dikembangkan, kedua, mengetahui shift share setiap sektor baik secara regional ataupun nasional.

\section{TINJAUAN PUSTAKA}

\subsection{Landasan Teori}

\subsubsection{Teori Economic Base}

Menurut Wang dan Hofie (2007: 136) teori Economic Base ditemukan oleh Piter De la Court (16181685) dengan pendapatnya industri yang berorientasi ekspor telah membuat kota Leiden kaya dengan devisa yang masuk. Devisa inilah yang membangun perekonomian kota.

Menurut Tarigan (2014: 28-29) teori Basis ekonomi (economic base theory) memiliki pemikiran bahwa hanya peningkatan ekspor yang akan mampu menaikkan laju pertumbuhan ekonomi wilayah, sementara itu yang bukan ekspor tidak bisa. Kegiatan ekonomi wilayah terbagi dua yaitu basis dan non basis. Sektor basis adalah sektor unggulan dimana produk dari sektor tersebut ditujukan untuk diekspor ke wilayah lain; bisa wilayah regional lain masih satu negara ataupun luar negeri.

\subsubsection{Teori Perubahan Struktural}

Menurut Kuncoro (2010: 41) yang menjadi pelopor teori perubahan struktural adalah Hollis Chenery. Inti dari perubahan struktural (structural change) adalah adanya proses pembangunan yang dialami oleh banyak negara sedang berkembang yang semula menitikberatkan sektor pertanian tradisional kemudian beralih ke sektor industri manufacturing sebagai mesin utama penggerak pertumbuhan ekonomi negaranya

\subsubsection{Teori Pertumbuhan Adam Smith}

Boediono (2012) mengatakan pertumbuhan output menurut Adam Smith terdiri dari tiga unsur pokok yaitu: a. Sumberdaya alam; b. Sumberdaya manusia (jumlah penduduk), dan c. Stok barang kapital yang ada. Sumberdaya alam yang ada di negara tersebut merupakan batas maksimum bagi pertumbuhan ekonomi negara tersebut. Sumberdaya manusia atau jumlah penduduk akan mengikuti perkembangan dalam proses produksi: semakin besar produksi maka semakin banyak penduduk yang bekerja, sebaliknya jika poses produksi mengalami pengurangan maka jumlah penduduk yang bekerja juga akan berkurang. Stok kapital akan menentukan output yang tersedia. Semakin banyak stok kapital yang diinvestasikan maka semakin banyak output yang akan diproduksi. Keberadaan stok kapital yang dikombinasikan dengan sumberdaya yang terbatas jumlahnya.

\subsubsection{Teori Pertumbuhan Ekonomi Solow}

Teori Pertumbuhan Ekonomi model Solow merupakan teori yang menganggap pertumbuhan ekonomi merupakan interaksi antara faktor-faktor produksi yang meliputi: pertumbuhan modal, pertumbuhan angkatan kerja dan kemajuan teknologi. 


\subsection{Penelitian Sebelumnya}

Defriana, et al (2015) meneliti tentang analisis sektor basis dan keunggulan kompetitif kabupaten dan kota di Propinsi Kalimantan Tengah. Hasil analisisnya: tiap-tiap kabupaten dan kota memiliki sektor basis masing-masing sesuai dengan kondisi daerah. Analisis LQ menunjukkan sektor pertanian merupakan sektor basis. Analisis SS menunjukkan keunggulan kompetitif dan spesialisasi didominasi oleh sektor pertanian juga.

Adi (2017) meneliti tentang sektor-sektor menurut Lapangan Usaha PDRB Jawa Timur memakai LQ dan SS. Hasil analisis untuk LQ kegiatan basis adalah sektor-sektor: Industri Pengolahan; Pengadaan Air, Pengolahan Limbah, Sampah; Perdag. Besar dan Retail; Reparasi Mobil dan Motor; Akomodasi dan Makan Minum; Informasi dan Komunikasi; sementara itu untuk SS menemukan National Share semua sektor memiliki pertumbuhan yang lebih cepat dibandingkan dengan pertumbuhan nasional; dalam nilai Industrial mix diketahui sektor yang perkembangannya lamban adalah: Pertanian, Kehutanan, Perikanan; Pertambangan dan Penggalian; Pengadaan Listrik dan Gas; Perdag. Besar dan Eceran, Rep. Mobil dan Sepeda Motor; dalam nilai Differential Shift diketahui sektor: Pertanian, Kehutanan, Perikanan; Pengadaan Listrik dan Gas; Pengadaan Air, Pengelolaan Sampah, Limbah; Konstruksi; Transportasi dan Perdagangan; Informasi dan Komunikasi; Jasa Keuangan dan Asuransi; Jasa Perusahaan; Jasa Pendidikan; Jasa Kesehatan dan Kegiatan Sosial; dan Jasajasa lainnya merupakan sektor yang perkembangannya lebih lambat.

\section{METODE PENELITIAN}

Data yang diamati adalah data sekunder yang diperoleh dari www.Badan Pusat Statistik.go.id/Satistik Indonesia pelbagai tahun penerbitan maupun Statistik Provinsi DKI, Banten, Jawa Barat, DI Jogjakarta, Jawa Tengah, dan Jawa Timur. Periode yang diamati adalah dua tahun yaitu tahun 2011 dan 2017.

Variabel yang diamati adalah jumlah pekerja setiap sektor Menurut Lapangan Usaha dalam Produk Domestik Regional Bruto (PDRB) propinsi Jawa Timur dan PDRB seluruh propinsi di pulau Jawa. Satuan yang diteliti adalah orang.

Model yang dipakai adalah analisis Location Quotient (LQ) dan Shift-Share (SS).

\section{Analisis Location Quotient (LQ):}

Analisis Location Quotient adalah perbandingan sektor/industri di suatu daerah (propinsi) terhadap besarnya peran sektor/industri tersebut secara nasional (seluruh pulau Jawa) (Tarigan, 2014: 82). Sektor/industri yang diperbandingkan di daerah tersebut haruslah sama dengan sektor/industri secara nasional dan waktu (tahun) harus sama juga. Misalnya sektor Manufacturing di PDRB Jatim tahun 2016 harus diperbandingkan dengan sektor Manufacturing secara nasional tahun 2016 juga.

Penelitian ini nantinya memakai analisis LQ untuk menganalisis proporsi jumlah pekerja setiap sektor pada propinsi Jawa Timur terhadap proporsi jumlah pekerja setiap sektor pada seluruh propinsi di pulau Jawa . Ada 9 (sembilan) sektor pada PDRB maupun PDRB (pulau Jawa) Menurut Lapangan Usaha.

Formula Analisis LQ (Putra, 2011: 163) sebagai berikut:

$$
\mathrm{LQ}=\left[\left(\mathrm{X}_{\text {ir }} / \mathrm{X}_{\mathrm{r}}\right) /\left(\mathrm{X}_{\text {in }} / \mathrm{X}_{\mathrm{n}}\right)\right]
$$

Dimana :

LQ = Location Qutient; $X_{\text {ir }}=$ pekerja sektor $i$ di daerah; $X_{r}=$ jumlah pekerja seluruh sektor di daerah; $X_{\text {in }}=$ jumlah pekerja sektor i di tingkat nasional; dan $X_{n}=$ jumlah pekerja seluruh sektor di tingkat nasional. Sektor $\mathrm{i}$ maksudnya adalah sektor: 1. Pertanian,Kehutanan, Perburuan, dan Perikanan; 2. Pertambangan dan Penggalian, 3. Industri Pengolahan, 4. Listrik, Gas, dan Air, 5. Bangunan, 6. Perdagangan Besar, Eceran, Rumah Makan, dan Hotel, 7. Angkutan, Pergudangan, dan Komunikasi, 8. Keuangan, Asuransi, Usaha Persewaan Bangunan, Tanah, dan Jasa Perusahaan, dan 9. Jasa Sosial/perorangan.

Aturan dalam analisis LQ adalah (Tarigan, 2014: 82-83):

a). Jika LQ $>1$, artinya sektor tersebut lebih besar peranannya di daerah lokal (setempat) daripada peranannya secara nasional. Inilah yang disebut sektor basis.

b). Jika LQ < 1, artinya sektor tersebut lebih kecil peranannya di daerah lokal (setempat) daripada peranannya secara nasional.

c). Jika $L Q=1$, artinya sektor tersebut sama peranannya di daerah lokal (setempat) dengan peranannya secara nasional.

Sektor yang memiliki nilai LQ > 1 disebut sektor basis (base sector) dan lainnya disebut sektor bukan 
basis (unbase sector). Nilai LQ paling kecil dapat dimaknai sektor tersebut merupakan sektor paling kecil peranannya di daerah daripada secara nasional dan paling perlu mendapatkan perhatian khusus agar mampu meningkat seperti peranan sektor lainnya. Nilai LQ yang paling besar artinya sektor tersebut paling besar peranannya secara lokal (daerah) daripada nasional.

\section{Analisis Shift-Share}

Tujuan analisis shift-share adalah untuk membandingkan perbedaan laju pertumbuhan masing-masing sektor/industri yang ada di daerah dengan nasional (Tarigan, 2014: 85), sedangkan menurut Sjafrizal (2016: 189) manfaat SS adalah mengetahui faktor yang mempengaruhi dan menentukan pertumbuhan ekonomi di suatu daerah. Faktor-faktor tersebut berasal dari daerah itu sendiri, nasional bahkan luar negeri.

Tujuan tersebut dapat dijawab dengan analisis SS dengan langkah-langkah mencari National Share, Industrial Mix, dan Competitive Position (Putra, 2011: 169-171). Uraian mereka sebagai berikut:

National Share $(N S)===\rightarrow N S=X_{2011} \times\left(\varepsilon N P_{2}-1\right)$ dimana $\varepsilon N P_{2}$ adalah jumlah proporsi pekerja di masingmasing sektor secara nasional tahun 2017 terhadap pekerja di sektor yang sama secara nasional tahun 2011. $\mathrm{X}_{2011}$ adalah pekerja nasional masing-masing sektor tahun 2011.

Industrial Mix $(I M)===\rightarrow I M=X_{2011} \times\left(N_{2}-\varepsilon N P_{2}\right)$ dimana $N_{2}$ adalah proporsi pekerja nasional masingmasing sektor tahun 2017 terhadap pekerja nasional sektor yang sama tahun 2011. $\mathrm{X}_{2011}$ adalah pekerja nasional masing-masing sektor tahun 2011.

Competitive Position $===\rightarrow C P=X_{2011} \times\left(N_{1}-N_{2}\right)$ dimana $N P_{1}$ adalah proporsi pekerja masing-masing sektor pada setiap propinsi. $\mathrm{X}_{2011}$ adalah pekerja nasional masing-masing sektor tahun 2011.

\section{HASIL PENELITIAN}

Analisis data baik Location Quotient (LQ) maupun Shift-Share (SS) akan dipakai untuk running data berikut:

Tabel 4.1

Penduduk Berumur 15 Tahun ke Atas yang Bekerja

Selama Seminggu yang Lalu Berdasarkan Lapangan Pekerjaan

di Propinsi Jawa Timur dan Pulau Jawa Tahun 2011, 2017

\begin{tabular}{|r|r|r|r|r|}
\hline & \multicolumn{3}{|c|}{ JAWA TIMUR } & \multicolumn{1}{c|}{ PULAU JAWA } \\
\hline Sektor & \multicolumn{1}{|c|}{2011} & \multicolumn{1}{c|}{2017} & \multicolumn{1}{c|}{2011} & \multicolumn{1}{c|}{2017} \\
\hline 1 & 7.520 .067 & 6.713 .893 & 17.663 .828 & 15.264 .509 \\
\hline 2 & 132.588 & 158.435 & 434.465 & 481.210 \\
\hline 3 & 2.665 .473 & 3.016 .837 & 11.382 .123 & 12.924 .655 \\
\hline 4 & 24.399 & 55.908 & 126.820 & 225.941 \\
\hline 5 & 1.158 .525 & 1.423 .169 & 3.978 .800 & 5.085 .389 \\
\hline 6 & 3.908 .294 & 4.580 .393 & 15.105 .529 & 17.925 .215 \\
\hline 7 & 709.844 & 699.981 & 3.127 .252 & 3.481 .072 \\
\hline 8 & 362.314 & 503.394 & 1.814 .379 & 2.645 .671 \\
\hline 9 & 2.458 .836 & 2.947 .210 & 9.594 .733 & 11.443 .546 \\
\hline & & & & \\
\hline Jumlah & 18.940 .340 & 20.099 .220 & 63.227 .929 & 69.477 .208 \\
\hline
\end{tabular}

Sumber: Badan Pusat Statistik, diolah

Keterangan: 1. Pertanian,Kehutanan, Perburuan, dan Perikanan; 2. Pertambangan dan Penggalian, 3. Industri Pengolahan, 4. Listrik, Gas, dan Air, 5. Bangunan, 6. Perdagangan Besar, Eceran, Rumah Makan, dan Hotel, 7. Angkutan, Pergudangan, dan Komunikasi, 8. Keuangan, Asuransi, Usaha Persewaan Bangunan, Tanah, dan Jasa Perusahaan, dan 9. Jasa Sosial/perorangan. 
Dari Tabel 4.1 kita lihat bahwa jumlah pekerja dalam PDRB Menurut Lapangan Usaha Propinsi Jawa Timur dari tahun 2011 ke 2017 mengalami peningkatan sebesar 1.158 .880 orang yang didapatkan dari 20.099.220 orang dikurangi 18.940.340 orang. Untuk pulau Jawa jumlah pekerja dari tahun 2011 ke 2017 tumbuh sebanyak 6.249.279, yang didapatkan dari pengurangan 69.477 .208 pekerja dengan 63.227 .929 pekerja. Sektor yang paling banyak menyerap pekerja pada PDRB propinsi Jawa Timur adalah sektor 1. Pertanian,Kehutanan, Perburuan, dan Perikanan; 3. Industri Pengolahan; dan 6. Perdagangan Besar, Eceran, Rumah Makan, dan Hotel untuk tahun 2011 maupun tahun 2017, sedangkan untuk pulau Jawa adalah sektor 1. Pertanian,Kehutanan, Perburuan, dan Perikanan; 3. Industri Pengolahan; dan 6. Perdagangan Besar, Eceran, Rumah Makan, dan Hotel, sama dengan sektor pada propinsi Jawa Timur. Data pada pulau Jawa merupakan penjumlahan masing-masing pekerja menurut Lapangan Usaha mulai dari propinsi DKI Jakarta, Banten, Jawa Berat, DI. Yogjakarta, Jawa Tenggah, dan Jawa Timur. Data pulau Jawa berfungsi sebagai pembanding dalam running data baik itu dalam analisis LQ maupun Shift-share.

Data pada Tabel 4.1 penulis pakai untuk analisis data memakai analisis LQ dan hasilnya dapat dilihat pada tabel berikut ini:

Tabel 4.2

Hasil Analisis Location Quotient terhadap

Data Pekerja PDRB Propinsi Jawa Timur dan Pulau Jawa Tahun 2011, 2017

\begin{tabular}{|r|r|l|r|l|}
\hline \multicolumn{1}{|c|}{ Sektor } & \multicolumn{1}{|c|}{$\mathbf{2 0 1 1}$} & Keterangan & \multicolumn{1}{|c|}{$\mathbf{2 0 1 7}$} & Keterangan \\
\hline 1 & 1,42 & Basis & 1,52 & Basis \\
\hline 2 & 1,02 & Basis & 1,14 & Basis \\
\hline 3 & 0,78 & Non-Basis & 0,81 & Non-Basis \\
\hline 4 & 0,64 & Non-Basis & 0,86 & Non-Basis \\
\hline 5 & 0,97 & Non-Basis & 0,97 & Non-Basis \\
\hline 6 & 0,86 & Non-Basis & 0,88 & Non-Basis \\
\hline 7 & 0,76 & Non-Basis & 0,70 & Non-Basis \\
\hline 8 & 0,67 & Non-Basis & 0,66 & Non-Basis \\
\hline 9 & 0,86 & Non-Basis & 0,89 & Non-Basis \\
\hline & & & & \\
\hline & $\mathbf{7 , 9 8}$ & & $\mathbf{8 , 4 1}$ & \\
\hline
\end{tabular}

Sumber: Diolah dari Tabel 4.1

Analisis LQ dirangkum dalam Tabel 4.2. Dari Tabel 4.2 kita ketahui sektor-sektor basis maupun sektor nonbasis baik untuk tahun 2011 ataupun tahun 2017 yang dapat diuraikan lebih jauh: pada tahun 2011 memiliki kegiatan basis yaitu sektor 1. Pertanian,Kehutanan, Perburuan, dan Perikanan; dan 2. Pertambangan dan Penggalian; sedangkan pada tahun 2017 masih memiliki kegiatan basis yang sama dengan tahun 2011 yaitu sektor 1. Pertanian,Kehutanan, Perburuan, dan Perikanan; dan 2. Pertambangan dan Penggalian. Untuk lebih jelasnya akan peneliti uraikan berdasarkan sektor-sektor yang ada:

1. Sektor Pertanian,Kehutanan, Perburuan, dan Perikanan nilai LQ-nya naik dari 1,42 pada tahun 2011 menjadi 1,52 pada tahun 2017 karena adanya peningkatan proses produksi sehingga penyerapan tenaga kerja mengalami kenaikan. Diperkirakan sampai beberapa tahun ke depan sektor ini akan tetap menjadi sektor basis karena Jawa Timur dikenal sebagai lumbung pangan tingkat nasional.

2. Sektor Pertambangan dan Penggalian memiliki nilai LQ yang meningkat dari tahun 2011 ke 2017 semula 1,02 menjadi 1,14 karena semakin bertambahnya bahan galian yang dieksploitasi untuk memenuhi kebutuhan industri maupun diekspor, misalnya minyak dan gas. Tidak dapat dipungkiri bahwa ada bahan galian yang diimpor dari daerah lain, misalnya batubara sehingga dampak penyerapan tenaga kerja dinikmati oleh daerah penghasil yakni Kalimantan.

3. Sektor Industri Pengolahan memiliki nilai LQ sebesar 0,78 di tahun 2011 meningkat menjadi 0,81 pada tahun 2017. Peningkatan penyerapan tenaga kerja ini disyukuri karena adanya peningkatan sangat kecil peran sektor industri dalam sumbangannya terhadap PDRB Jawa Timur Atas Dasar Harga 
Konstan 2010 yaitu 29,03\% pada tahun 2011 menjadi 29,29\% pada tahun 2017.

4. Sektor. Listrik, Gas, dan Air memiliki nilai LQ yang sangat kecil karena masih sangat sedikit penduduk Jawa Timur yang memerlukan air PDAM yakni hanyalah penduduk di perkotaan saja sementara yang di pedesaan mengandalkan air tanah dari sumber lainnya. Konsumsi listrik dan gas juga meningkat seiring dengan peningkatan kapasitas produksi sektor industri maupun rumah tangga

5. Sektor Bangunan memiliki nilai LQ yang tetap yaitu 0,97. Penyerapan tenaga kerja pada sektor bangunan tidak meningkat seperti pertumbuhan bangunan itu sendiri karena bangunan besar maupun sedang mengandalkan teknologi modern.

6. Sektor Perdagangan Besar, Eceran, Rumah Makan, dan Hotel memiliki nilai LQ yang kecil meski meningkat. Hal ini terjadi karena sektor ini berperan di kota-kota besar sementara di wilayah pedesaan kurang berperan sehingga penyerapan tenaga kerja juga kecil.

7. Sektor Angkutan, Pergudangan, dan Komunikasi memiliki nilai LQ yang kecil dan cenderung turun. Penurunan ini karena lesunya angkutan roda empat baik di perkotaan maupun di pedesaan karena penduduk banyak yang memiliki angkutan roda dua bahkan sampai di pedesaan maupun di daerah pegunungan. Tidak dapat dipungkiri bahwa jumlah angkutan roda empat sebagai milik pribadi juga mengalami peningkatan seiring peningkatan kesejahteraan penduduk. Untuk jasa pergudangan hanya di perkotaan saja sementara di pedesaan hampir tidak ada sehingga nilai LQ-nya kecil.

8. Sektor Keuangan, Asuransi, Usaha Persewaan Bangunan, Tanah, dan Jasa Perusahaan memiliki nilai LQ yang kecil karena sektor industri selaku konsumen sektor ini mengalami pertumbuhan yang sangat kecil. Diharapkan untuk tahun mendatang pertumbuhan sektor industri di Jawa Timur meningkat maka peran sektor keuangan, asuransi juga akan mengalami peningkatan.

9. Sektor Jasa Sosial/perorangan memiliki nilai LQ yang kecil karena peran ekonominya kecil. Diperkirakan beberapa tahun ke depan peran sektor jasa sosial ini akan membaik seiring dengan membaiknya perekonomian Jawa Timur sehingga penyerapan tenaga kerja juga meningkat.

Bilamana tujuan utama adalah memperkuat pertumbuhan ekonomi maka sektor basislah yang harus diutamakan yaitu sektor 1 dan 2 harus menjadi fokus utama untuk ditingkatkan lebih lanjut dalam peningkatan pertumbuhan ekonomi karena dua sektor tersebut yang mampu memimpin dalam penyerapan tenaga kerja, sedangkan bila tujuan utamanya adalah peningkatan sektor-sektor yang non-basis menjadi basis maka perlu difokuskan terhadap sektor yang memiliki nilai LQ paling rendah. Keberhasilan peningkatan pertumbuhan sektor non-basis ke sektor basis akan lebih memeratakan pertumbuhan semua sektor dalam penyerapan jumlah pekerja.

Hasil analisis LQ yang menyatakan sektor 1. Pertanian; dan sektor 2. Penggalian sebagai sektor basis mirip dengan penelitian Defriana, et al (2015) dimana Analisis LQ menunjukkan sektor 1. Pertanian merupakan sektor basis, sementara itu penelitian Nur AR, et al (2015) mengatakan untuk Mojokerto selama tahun penelitian 2009-2013 yang menjadi sektor basis adalah: sektor 1. Pertanian, 2. Pertambangan dan Penggalian, 3. Industri Pengolahan, dan 7. Pengangkutan dan Komunikasi.

Hasil analisis LQ ini berbeda dengan penelitian Adi (2017) yang menyatakan bahwa sektor 1. Pertanian bukanlah sektor basis, sedangkan analisis LQ menghasilkan nilai National Share semua sektor positif artinya pertumbuhan regional lebih tinggi bila dibandingkan dengan nasional; nilai proportional shift sektor yang perkembangannya lamban adalah sektor 1,2,3,5; nilai differential shift menyimpulkan mayoritas sektor di Jawa Timur kurang memiliki daya saing.

Pertumbuhan penyerapan tenaga kerja masing-masing sektor berbeda baik itu untuk propinsi Jawa Timur maupun untuk pulau Jawa. Pertumbuhan penyerapan tenaga kerja antara kedua wilayah (Jawa Timur dan pulau Jawa) akan di-running memakai analisis Shift-Share. Berikut hasil analisis Shift-share terhadap data disajikan ke dalam tabel: 
Tabel 4.3

Hasil Analisis Shift-Share terhadap

Data Pekerja PDRB Propinsi Jawa Timur dan Pulau Jawa Tahun 2011, 2017

\begin{tabular}{|c|c|c|c|c|c|c|c|}
\hline \multicolumn{3}{|c|}{ JAWA TIMUR } & \multicolumn{2}{|c|}{ PULAU JAWA } & \multirow{2}{*}{$\begin{array}{c}\text { National } \\
\text { Share } \\
\end{array}$} & \multirow{2}{*}{$\frac{\text { Industrial }}{\text { Mix }}$} & \multirow{2}{*}{$\begin{array}{c}\text { Competitive } \\
\text { Position } \\
\end{array}$} \\
\hline Sektor & 2011 & 2017 & 2011 & 2017 & & & \\
\hline 1 & 7.520 .067 & 6.713 .893 & 17.663 .828 & 15.264 .509 & 192.702 & - $\quad 1.214 .170$ & 215.294 \\
\hline 2 & 132.588 & 158.435 & 434.465 & 481.210 & 3.398 & 10.868 & 11.582 \\
\hline 3 & 2.665 .473 & 3.016 .837 & 11.382 .123 & 12.924 .655 & 68.303 & 292.928 & 9.867 \\
\hline 4 & 24.399 & 55.908 & 126.820 & 225.941 & 625 & 18.445 & 12.439 \\
\hline 5 & 1.158 .525 & 1.423 .169 & 3.978 .800 & 5.085 .389 & 29.687 & 292.523 & 57.566 \\
\hline 6 & 3.908 .294 & 4.580 .393 & 15.105 .529 & 17.925 .215 & 100.150 & 629.395 & 57.446 \\
\hline 7 & 709.844 & 699.981 & 3.127 .252 & 3.481 .072 & 18.190 & 62.123 & 90.175 \\
\hline 8 & 362.314 & 503.394 & 1.814 .379 & 2.645 .671 & 9.284 & 156.717 & 24.921 \\
\hline 9 & 2.458 .836 & 2.947.210 & 9.594 .733 & 11.443 .546 & 63.008 & 410.786 & 14.580 \\
\hline Total & 18.940 .340 & 20.099 .220 & 63.227 .929 & $69.477 .208,00$ & $485.346,01$ & $659.615,13$ & $13.918,86$ \\
\hline
\end{tabular}

Sumber: BPS, diolah

Dari Tabel 4.3 kita ketahui: nilai National Share semua sektor positif; nilai Industrial Mix sektor 1. Pertanian,Kehutanan, Perburuan, dan Perikanan bernilai negatif; Competitive Position yang bernilai negatif ialah sektor 3,5,6,7, 8. atau sektor 3. Industri Pengolahan, 5. Bangunan, 6. Perdagangan Besar, Eceran, Rumah Makan, dan Hotel, 7. Angkutan, Pergudangan, dan Komunikasi, 8. Keuangan, Asuransi, Usaha Persewaan Bangunan, Tanah, dan Jasa Perusahaan.

Pada Kolom National Share semua sektor positif artinya sektor-sektor tersebut mulai sektor $1 \mathrm{~s} / \mathrm{d} 9$ memiliki pertumbuhan penyerapan tenaga secara regional (Jawa Timur) lebih besar bila dibandingkan pertumbuhan penyerapan tenaga kerja secara nasional (Pulau Jawa) secara rata-rata. Pada kolom Industrial Mix sektor 1. Pertanian,Kehutanan, Perburuan, dan Perikanan memiliki tingkat pertumbuhan penyerapan tenaga kerja paling lamban; pada kolom Competitive Position sektor-sektor 3,5,6,7,8 merupakan sektor-sektor yang tidak mampu bersaing dengan wilayah lainnya dalam penyerapan tenaga kerja (daya saing rendah).

\section{SIMPULAN DAN SARAN}

Dari pembahasan dapat disimpulkan: Hasil analisis LQ untuk propinsi Jawa Timur pada tahun 2011 memiliki kegiatan basis sektor 1 dan 2, dan pada tahun 2017 memiliki kegiatan basis yang sama yaitu sektor 1 dan 2. Secara umum dapat dikatakan bahwa propinsi Jawa Timur memiliki sektor basis adalah sektor primer (1 dan 2). Tidak ada perubahan dari sektor non-basis ke sektor basis atau sebaliknya, dari sektor basis ke sektor non-basis.

Hasil analisis Shift Share dari tahun 2011 ke 2017 untuk propinsi Jawa Timur menunjukkan National Share semua sektor memiliki tingkat pertumbuhan penyerapan tenaga kerja regional (Jawa Timur) lebih tinggi bila dibandingkan dengan tingkat nasional (pulau Jawa); pada kolom Industrial Mix sektor 1 merupakan sektor yang tumbuh lebih lamban bila dibandingkan dengan nasional dalam hal penyerapan tenaga kerja; pada kolom Competitive Position 3,5,6,7,8 merupakan sektor yang tidak mampu bersaing dengan wilayah lainnya.

Dari pelbagai pembahasan dan simpulan yang telah dituturkan maka penulis memberikann saran kepada Pemerintah Daerah Propinsi Jawa Timur yaitu perlu mengembangkan sektor primer (1 dan 2) yang merupakan sektor basis dalam usaha penyerapan tenaga kerja yang ada serta meningkatkan penyerapan tenaga kerja untuk sektor 3,5,6,7,dan 8 agar memiliki daya saing tinggi dibandingkan regional lainnya.

\section{DAFTAR PUSTAKA}

Adi, Lumadya, 2017. Analisis LQ, Shift-Share, dan Proyeksi Produk Domestik Regional Bruto Jawa Timur 2017, Jurnal Akuntansi \& Ekonomi FE.UN PGRI Kediri, Volume 2 No. 1, Maret 2017, halaman 79-90.

Defriana, E., Tiawon, H., dan Suluh, S.I. 2015. Analisis Sektor Basis dan Keunggulan Kompetitif Kabupaten dan Kota di 
Propinsi Kalimantan Tengah, Jurnal Growth, Jurnal Magister Imu Ekonomi, Universitas Palangka Raya,Volume 1 No. 2 Desember 2015, halaman 30-39.

Kuncoro, M. 2010. Dasar-dasar Ekonomika Pembangunan, Edisi Kelima, Cetakan Pertama September 2010, Penerbit dan Pencetak UPP STIM YKPN Yogjakarta.

Mankiw, N.G. 2007. Makroekonomi, Harvard University, Edisi Keenam (terjemahan), Erlangga, Jakarta.

Nur AR, C., Putri, P., Hidayah, U. dan Yuliastika M. 2015. Identifikasi dan Analisis Persoalan Ekonomi Wilayah di Kabupaten Mojokerto, Tugas 4 Ekonomi Wilayah.

Putra, M.F. 2011. Studi Kebijakan Publik dan Pemerintahan dalam Perspektif Kuantitatif, Universitas Brawijaya (UB) Press, Cetakan Pertama, April 2011, Malang.

Santika P., Endy H., Anisa HK., dan Azizah FE. 2016. Arahan Pengembangan Ekonomi Wilayah dengan Konsep Agropolitan Kabupaten Lamongan.

Sjafrizal. 2016. Perencanaan Pembangunan Daerah dalam Era Otonomi, PT. Rajagrafindo Persada, Cetakan ke-3 Maret 2016.

Tarigan, R. 2014. Ekonomi Regional Teori dan Aplikasi, Edisi Revisi, Cetakan Ketujuh, Maret 2014, Diterbitkan oleh PT. Bumi Aksara, Jakarta.

Wang, X. Dan Hofie, R. 2007. Research Methods in Urban and Regional Planning, Spinger-Verlag Gambri Berlin Heidelberg dan Tsinghua University Press, Beijing.

Yogi, Pradono, Adiwan Aritenang, 2014. Pengantar Ekonomika Wilayah Pendekatan Analisis Praktis, ITB Press, Bandung.

Badan Pusat Statistik, Statistik Indonesia, pelbagai tahun penerbitan.

Badan Pusat Statistik, Propinsi Jawa Timur dalam angka, pelbagai tahun penerbitan. 